\title{
New Thrombolytic Agent from Endophytic Fungi and Lignosus rhinocerus
}

\author{
Mohd Sidek Ahmad*, Zainon Mohd Noor and Zaidah Zainal Ariffin
}

A601, Mycology Lab, Faculty of Applied Sciences, Universiti Teknologi MARA 40450 Shah Alam, Selangor, Malaysia

\begin{abstract}
Thrombosis and cardiovascular-related diseases can be caused by fibrin aggregation. Thrombolytic agents have been used to treat thrombolytic problems and cardiovascular-related diseases. There had been searches for new thrombolytic agents from bacteria, fungi, insects and fermented foods. To name a few, recently fungi such as Aspergillus oryzae KSK-3, Fusarium sp. CPCC 480097 and Fusarium sp. BLB were found able in producing protease fibrinolytic enzymes. Potential protease fibrinolytic enzymes were observed from Lignosus rhinocerus bought from Orang Asli of Sungei Perak. Out of the six (6) sclerotia used, one of them, LR-1, produced the biggest clear zone on Skim Milk Agar with a diameter of $1.31 \mathrm{~cm}$. Fibrin plate assay of LR-1 showed that it produced a clear zone of $0.97 \mathrm{~cm}$ when the plate was incubated for 18 hours at $37^{\circ} \mathrm{C}$ Leaves of Hibiscus sp. were sterilised with $70 \%$ alcohol and $70 \%$ sodium hypochlorite. The leaves were then cut into pieces of $4 \mathrm{~cm}$ and placed on Potato Dextrose Agar plate. Fungi grown from the leave pieces were sub cultured onto new Potato Dextrose Agar. This then showed that Lignosus rhinocerus had protease and fibrinolytic activities. Sixteen (16) endophytic fungi were isolated from Hibiscus sp. leaves from six locations in Shah Alam, Selangor. Two endophytic fungi, FH-3 and S-13 showed protease activities; clear zones of $2.89 \mathrm{~cm}$ and 2.42 were seen.after 4 days incubation at $27^{\circ} \mathrm{C}$. FH-3 had fibrinolytic activity which was observed by the $1.98 \mathrm{~cm}$ diameter clear zone on fibrin plate.
\end{abstract}

Keywords: Fibrinolytic enzyme, thrombolytic agent, endophytic fungi, Lignosus rhinoceros.

\section{INTRODUCTION}

The primary protein component of blood clot is fibrin, formed from fibrinogen by thrombin (EC 3.4.21.5) [1]. When blood vessels get blocked, thrombosis occurs because of fibrin which leads to myocardial infarction and cardiovascular diseases. Cardiovascular diseases, high blood pressure, acute myocardial infarction, ischemic heart disease, valvular heart disease, peripheral vascular disease, arrhythmias, stroke, have been known to be one of the major causes of death throughout the world [2]. Thrombolytic agents have been extensively used in the therapeutic treatment of thrombosis. Thrombolytic agents are differentiated by two different mechanisms. The first one is plasminogen activators, such as tissue-type plasminogen activator (t-PA) [3] and urokinase [4]. This type can activate the endogenous fibrinolytic system and generate plasmin from plasminogen. The second type is plasmin-like proteins, such as lumbrokinase [5], serine protease [6, 7] and metalloprotease [8]. This seond type can directly hydrolyze fibrin into fibrin degradation products, thus dissolving the thrombin rapidly and completely [9]. Although widely used, type one thrombolytic agents have undesirable side effects, low specificity, and are relatively expensive. The search for fibrinolytic enzymes from various sources has to go on because of the above reasons [10].

*Address correspondence to this author at the A601, Mycology Lab, Faculty of Applied Sciences, Universiti Teknologi MARA 40450 Shah Alam, Selangor, Malaysia; Tel: +603 55438456;

E-mail: sidekahmad77@yahoo.co.uk

\section{MATERIALS}

Fibrinogen, Thrombin, Plasmin from Calsbiochem, Germany. Skim milk, Potato dextrose from Oxoid, England.

\section{METHODOLOGY}

\section{Sampling of Lignosus Rhinocerus}

Sclerotia of Lignosus rhinocerus were bought from Orang Asli of Sungei Perak. There were 6 samples and they were labelled as LR-1, LR-2 LR-3 LR-4 LR-5 and LR-6.

\section{Isolation of Endophytic Fungi from Hibiscus Leaves}

The Hibiscus leaves collected from several places around Shah Alam, Selangor were surface sterilised with alcohol and $70 \%$ sodium chloride. The leaves were cut into pieces and placed on Potato Dextrose Agar. These plates were incubated for 3 to 5 days at $27^{\circ} \mathrm{C}$. Fungi that grew from cut leaves were sub cultured onto new Potato Dextrose Agar.

\section{Protease Bioassay}

\section{Lignosus Rhinocerus}

Samples were homogenized in liquid nitrogen using a Retsch Mixer mill. The powdered samples were diluted in sterile distilled water. Skim Milk Agar was used to detect the presence of protease. Wells were bored onto the Skim Milk Agar using a cork borer. Twenty (20) $\mu \mathrm{L}$ of the Lignosus rhinocerus diluted samples were placed in the wells prepared, then incubated at $37^{\circ} \mathrm{C}$ for 24 hours. Clear zones around the wells indicated that the protein in the Skim Milk Agar had been degraded by protease in the samples. 


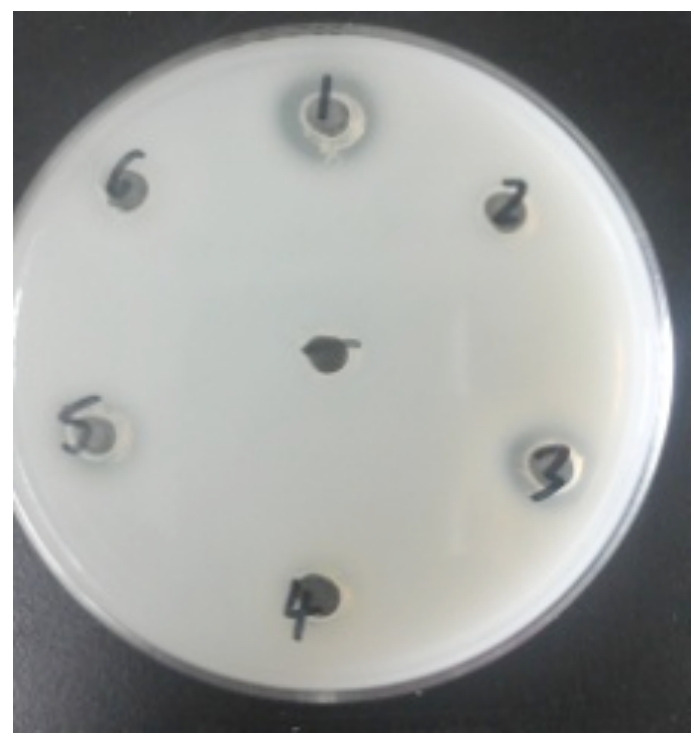

Fig. (1). Lignosus rhinocerus Protease present on Skim Milk Agar.

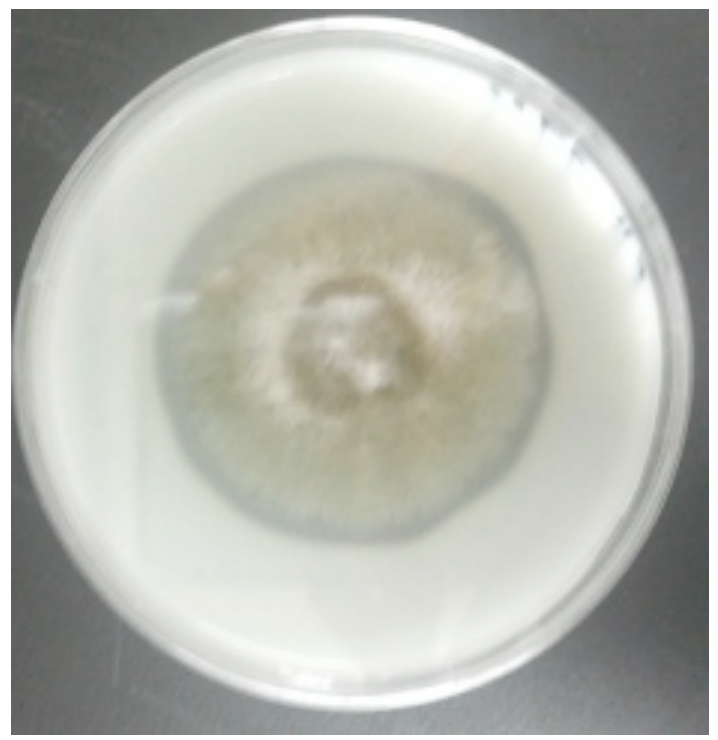

Fig. (2). Endophyte FH-3; Protease present on Skim Milk Agar.

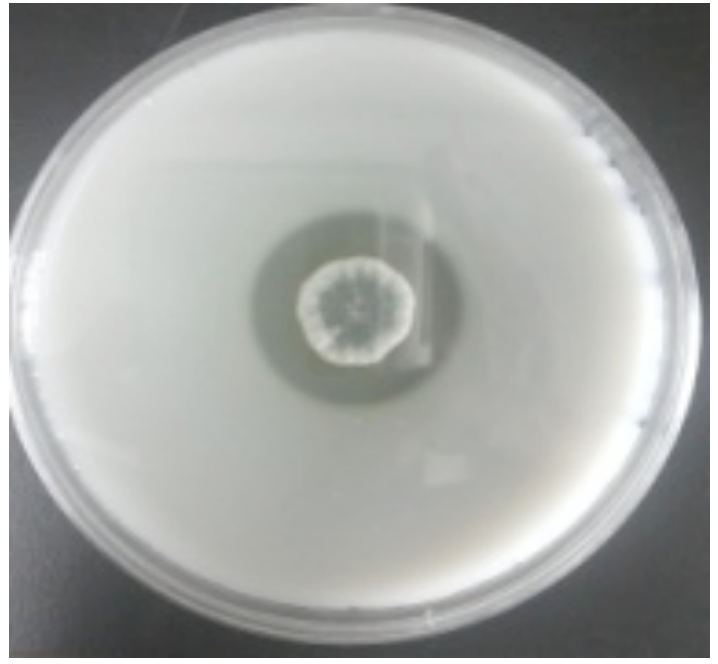

Fig. (3). Endophyte S-13; Protease present on Skim Milk Agar. 


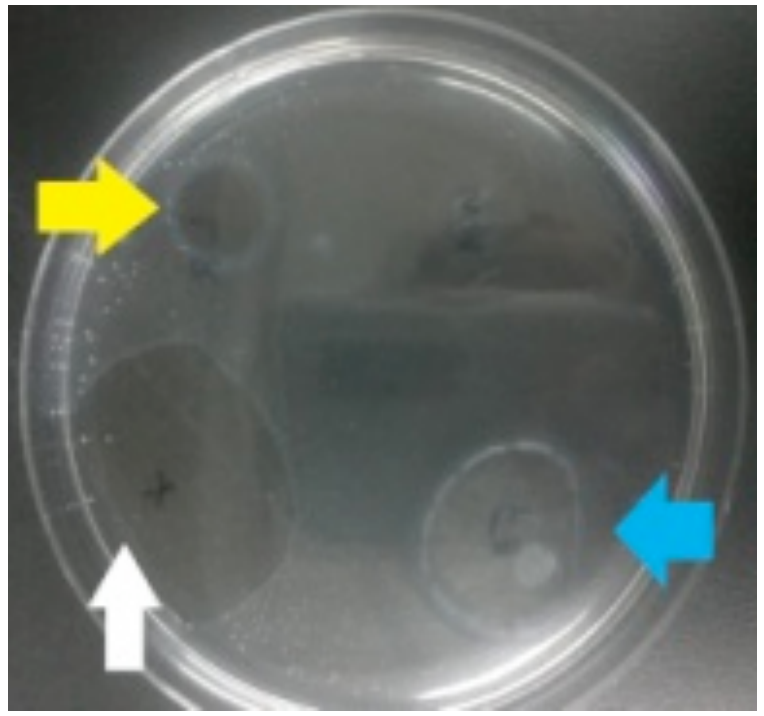

Fig. (4). Lignosus rhinocerus (Yellow) and Endophyte FH-3 (Blue) on Fibrin plate.

Table 1. Diameter Clear Zone of Samples (FH-3, S-13, LR-1, LR-3, LR-5) on Skim Milk Agar

\begin{tabular}{|c|c|c|c|c|c|}
\hline Diameter(Cm)\Time(H) & FH-3 & S-13 & LR-1 & LR-3 & LR-5 \\
\hline \hline 24 & 1.04 & 0.71 & 1.31 & 0.98 & 0.47 \\
\hline 96 & 2.42 & 2.89 & - & - & - \\
\hline
\end{tabular}

Table 2. Diameter Clear Zone of Samples (FH-3 and LR-1) on Fibrin Plate

\begin{tabular}{|c|c|c|c|c|c|}
\hline Diameter(Cm)\Time(H) & Positive (Plasmin) & Negative $\left(\mathbf{D H}_{\mathbf{2}} \mathbf{0}\right)$ & LR-1 & FH-3 & \\
\hline \hline 24 & 3.64 & 0 & 0.97 & 1.98 & \\
\hline
\end{tabular}

\section{Endophytic Fungi}

Sixteen (16) endophytic fungi collected from the Hibiscus leaves were cultured on Skim Milk Agar plates. Endophytic fungi after 48 hours in Potato Dextrose broth were sub cultured onto Skim Milk Agar. As the fungi grew, clear zones became visible around the fungal colony which represented protease activity against protein in the Skim Milk Agar.

\section{Fibrinolytic Activity}

Fibrinolytic activity was detected by using fibrin plates [11]. Fibrinolytic assay was done using a modified method from Astrup and Mullertz [11]. Five (5) $\mathrm{mL}$ fibrinogen solution, 10U thrombin solution and $5 \mathrm{~mL} 1 \%$ agarose were mixed together in a petri dish. The enzyme sample $(10 \mu \mathrm{L})$ was dropped onto the plate and incubated for 18 hours at $37^{\circ} \mathrm{C}$. Clear zones on the plates were measured and recorded and represented fibrinolytic activities of the enzymes.

\section{RESULTS AND DISCUSSION}

\section{Protease Bioassay}

Proteolytic activities were observed in Lignosus rhinocerus samples, LR-1 to LR-6 and the two endophytes, FH-3 and S-13. The activity was shown by the formation of clear zones around samples cultured on Skim Milk Agar (Figs. 1, 2 and 3). Diameters of these clear zones were tabulated in Table 1. Table 2 showed that out of six Lignosus rhinocerus samples, only three (3) showed protease activities. LR-1 produced a clear zone of $1.31 \mathrm{~cm}$ which is the highest from all three positives for protease activity. The other two LR samples have moderate sized clear zones (LR$3,0.98 \mathrm{~cm}$ and LR-5 $0.47 \mathrm{~cm}$ ). The endophytes, FH3 and $\mathrm{S} 13$, showed protease activities of by formation of clear zones around their colonies at 96 hours in $27^{\circ} \mathrm{C}$. FH-3 has a clear zone of $2.89 \mathrm{~cm}$ and S-13 has a slightly smaller clear zone of $2.42 \mathrm{~cm}$.

It can be seen that the endophytic fungi seemed to produce more proteolytic activity than Lignosus rhinocerus. This may be due to the endophytic fungi are growing microorganisms; therefore they are still producing the enzymes. But this is not so for the Lignosus rhinocerus as the samples are sclerotia, which are parts of the mushrooms. Unless Lignosus rhinocerus are grown then there is a possibility that there will be higher proteolytic activity. Also in comparison, among the 6 Lignosus rhinocerus samples, 3 did not show proteolytic activity and between the 3 that produced clear zones, the sizes of clear zones also differ. Their proteolytic potentials may differ due to differences nutrient composition of these mushrooms.

Lignosus rhinocerus samples LR-1, LR-3 and LR-5 showed the presence of protease after 24 hours incubation in $37^{\circ} \mathrm{C}$. Isolated endophytes showed the ability to produce 
protease after incubation at $27^{\circ} \mathrm{C}$ for 96 hours. Results are tabulated on Table 1.

\section{Fibrinolytic Activity}

Positive samples with protease activities were tested for fibrinolytic activity on Fibrin plates. Fibrinolytic activity was determined by ring formation around the samples indicating degradation of fibrin. This is shown on Fig. (4) where the yellow arrow showing LR-1, blue arrow is FH-3 and the white arrow is the positive control (plasmin). LR-1 produced $0.97 \mathrm{~cm}$ and $\mathrm{FH}-3$ produced $1.98 \mathrm{~cm}$ clear zone as shown in Table 2. This could prove that the protease samples from these endophytes and mushroom are with fibrinolytic properties; Serine Protease from Aspergillus orzyae KSK-3 and Fusarium sp. BLB [6, 7] or Metalloprotease from Armillaria mellea) [8].

\section{CONCLUSION}

In conclusion, isolated endophytic fungi and Lignosus rhinocerus have positive protease and fibrinolytic activities.

\section{CONFLICT OF INTEREST}

The authors confirm that this article content has no conflicts of interest.

\section{ACKNOWLEDGEMENT}

This study is funded by UiTM RIF grant 600RMI/DANA 5/3/RIF (144/2012).

\section{REFERENCES}

[1] Voet, D. Voet, J.G. Biochemistry Book; John Wiley, New York; 1087-10951990, 1991

[2] Simkhada, J.R.; Mander, P.; Cho, S.S.; Yoo, J.C.; A novel fibrinolytic protease from Streptomyces sp. CS684. Process. Biochem., 2010, 45, 88-93.

[3] Collen, D.; Lijnen, H.R. Tissue-type plasminogen activateor a historical perspective account $J$. Thromb. Haemost., 2004, 2 , 541546.

[4] Duffy, M.J. Urokinase Plasminogen Activator and Its Inhibitor, PAI-1, as Prognostic Markers in Breast Cancer: From Pilot to Level 1 Evidence Studies. Clin. Chem., 2002, 8, 1194-1197.

[5] Mihara, H.; Sumi, H.; Yoneta, T.; Mizumoto, H.; Ikeda, R.; Seiki, M.; Maruyama, M. A novel fibrinolytic enzyme extracted from the earthworm, Lumbricus rubellus. Jpn J. Physiol., 1991, 41, 461-472.

[6] Shirasaka, N.; Naitou, M.; Okamura, K.; Kusuda, M.; Fukuta, Y.; Terashita, T. Purification and characterization of a fibrinolytic protease from Aspergillus oryzae KSK-3. Springer Mycosci., 2012, $1,16-17$.

[7] Sugimoto, S.; Fujii, T.; Morimiya, T.; Johdo, O.; Nakamura, T. The fibrinolytic activity of a novel protease derived from a tempeh producing fungus, Fusarium sp. BLB. Biosci. Biotechnol. Biochem., 2007, 71, 2184-2189.

[8] Lee, S.Y.; Kim, J.S.; Kim, J.E.; Sapkota, K.; Shen, M.H.; Kim, S.; Chun, H.S.; Yoo, J.C.; Choi, H.S.; Kim, M.K.; Kim, S.J. Purification and characterization of fibrinolytic enzyme from cultured mycelia of Armillaria mellea. Protein Expr. Purif., 2005, 43, 10-17.

[9] Wu, B.; Wu, L.; Chen, D.; Yang, Z.; Luo, M. Purification and characterization of a novel fibrinolytic protease from Fusarium sp. CPCC 480097. J. Ind. Microbiol. Biotechnol., 2009, 36, 451-459.

[10] Choi, D.B.; Cha, W.S.; Park, N.; Kim, H.W.; Lee, J.H.; Park, J.S.; Park, S.S. Purification and characterization of a novel fibrinolytic enzyme from fruiting bodies of Korean Cordyceps militaris. Bioresour Technol., 2011, 102, 3279-3285.

[11] Astrup, T.; Mullertz, S. The fibrin plate method for estimating fibrinolytic activity. Arch. Biochem. Biophys., 1952, 40, 346-351.

Received: May 29, 2013

(C) Ahmad et al.; Licensee Bentham Open.

This is an open access article licensed under the terms of the Creative Commons Attribution Non-Commercial License (http://creativecommons.org/licenses/by$\mathrm{nc} / 3.0 /$ ), which permits unrestricted, non-commercial use, distribution and reproduction in any medium, provided the work is properly cited 